\title{
DISORDERS OF THE INTESTINAL FLORA AND IT IS EFFECT ON SKELETAL SYSTEM DISEASES
}

DOI: 10.36740/WLek202009105

\author{
Agnieszka Tomczyk-Warunek', Anna Dubiel', Ewa Poleszak², Rudolf Blicharski', Maciej Dobrzyński \\ 'CHAIR AND DEPARTMENT OF REHABILITATION AND ORTHOPAEDICS, MEDICAL UNIVERSITY OF LUBLIN, LUBLIN, POLAND \\ 2DEPARTMENT OF APPLIED AND SOCIAL PHARMACY, LABORATORY OF PRECLINICAL TESTING, MEDICAL UNIVERSITY OF LUBLIN, LUBLIN, POLAND \\ ${ }^{3}$ DEPARTMENT OF CONSERVATIVE DENTISTRY AND PEDODONTICS, WROCLAW MEDICAL UNIVERSITY, WROCLAW, POLAND
}

\begin{abstract}
The intestinal microflora plays an important role in the proper functioning of human. It is complex, diverse and dynamic ecosystem that constantly strives to maintain homeostasis throughout the body. The process of acquiring intestinal microflora begins immediately after human birth. Elementary factors that determine the modification of the composition of the microflora are age, sex, diet, lifestyle. Determinate individual composition of the microflora. Microorganisms inhabiting the intestine perform various functions, from metabolic, immune to trophic. Early changes in the intestinal microflora are reflected in the state of human health. Recently, many studies have been carried out confirming the hypothesis that the bacterial flora of the gastrointestinal tract affects the normal metabolism of bone tissue, and disorders in its composition can lead to the appearance of bumps in the processes of physiological remodeling of bone tissue and contribute to the formation of many inflammations. Microorganisms that rot in the digestive tract regulate bone metabolism through three mechanisms: the impact on the immune system, the hormonal system and the impact on the absorption of minerals. Disorders in the microflora of the digestive tract can lead to the development of inflammatory bowel diseases, and as a consequence to the accelerated development of osteoporosis or arthrosis of the joints. The aim: To collect available publications confirming the impact of microflora on the skeletal system.
\end{abstract}

KEY WORDS: intestinal microflora, osteoporosis, arthrosis

Wiad Lek. 2020;73(9 p. I):1835-1839

\section{INTRODUCTION}

The digestive tract is inhabited by many microorganisms. Their number is 10 times greater than the number of the cell making up the human body [1]. The inhabitance of the digestive tract begins shortly after birth. Before mentioned microorganisms coexist in the state of symbiosis with the human organism [2]. In the microenvironment of the intestines the dominant species is bacteria, which are not very specified genetically. The microflora is individual to every human [3]. Only one third of the species inhabiting the digestive tract is the same between all humans [4]. The effect they have is modified by several factors, including: age, gender, eating habits, life style etc. Those microorganisms work in different ways, such as: they take effect on metabolism and absorbing minerals, they regulate electrolyte balance, they protect the organism against pathogens and they take effect on the whole immune system. It is clear to see that they play a crucial role in many areas at the same time keeping the homeostasis in the whole organism [3]. Disturbances in the microenvironment can cause changes in absorbing dietary nutrients (which take up to 65\% of the bone structure) and can also cause inflammation of intestines, which can lead to changes regarding remodeling and forming of the bone tissue $[5,6]$.

The aim: The purpose of this article is to collect information about the effect of the microflora on the skeleton system, and whether the changes in the homeostasis of the intestines have an effect on the frequency of occurring diseases in this system.

\section{REVIEW AND DISSCUSION}

\section{IMPACT OF THE MICROBIOME OF DIGESTIVE} TRACT ON REBUILDING OF BONE TISSUE

Microorganisms inhabiting the digestive tract play a significant role on homeostasis and health of the whole organism. In recent years many studies have been performed confirming the hypothesis, that the bacterial flora in the digestive tract has an effect on correct metabolism of bone tissue, and disturbances in it is contents may lead to changes in physiological processes of remodeling of the bone tissue [7]. The studies performed on animals deprived of intestinal microflora show, that the lack of digestive tract flora lead to the increase of density of the mineral cancellated bone and the number of bone trabecula on the surface, further causing the increase of volume of bone tissue, which in literature is marked as $\mathrm{BV} / \mathrm{TV}$ (bone volume density). The acquired results in this group of individuals are most likely connected to the inhibition of osteoclastic processes, which is caused by decreasing number of osteoclasts and their precursors. The resettlement of digestive tract over 
the course of three weeks caused the BMD (bone mineral density) in these animals to level out. The cause of this, most likely is that the intestinal microflora increased the activity of osteoclasts and therefore caused an increased rate of osteoclastic processes [8].

A study conducted in 2016 shows slightly different results [9]. It proves that control group that had the intestinal microflora in comparison to the other group, which did not possess the bacterial flora proved to have a significantly longer femur and better quality of cortical bone. No differences in the density of bone tissue could be spotted in neither group [9]. The acquired results in aforementioned experiments may differ, because they were conducted on different genders and different species. This fact proves the hypothesis, that the impact of microflora on bone structure is dependent on gender and the genes of a host because those two factors influence which microorganisms build the microenvironment of the digestive tract. The studies on mice deprived of the microorganisms inhabiting the digestive tract into which bacterial flora from donors in different ages and genders were transplanted showed a difference in the metabolism of bone tissue. Those differences were observed in the case of trabecular bone in these animals. This shows, that age and supplementation has a great impact on the way the microflora interacts with metabolism of the skeletal system [10]. The study was also conducted on animals, in which to influence the microenvironment of the digestive tract scientists used multitargeted antibiotics. In the group where animals received treatment there was a significant change in the density of the cortical bone, and its geometrical parameters [11]. All of the results show how the microflora of the digestive tract impacts the metabolic processes happening inside the bone tissue. There's hardly any research conducted on this flora on the organism of a human, but the results of the animal studies can be linked to the human organism and can be used as a base to future studies. The subject of the impact of the microflora has become more and more popular over the last years. Nowadays, research which study the impact of pathology of the microenvironment of the intestines only cover the inflammation of the digestive tract on the appearance of diseases of the cartilage tissue.

\section{REGULATION OF REBUILDING THE BONE TISSUE THROUGH MICROORGANISMS INHABITING THE DIGESTIVE TRACT}

Microorganisms inhabiting the digestive tract regulate the metabolism of the bone tissue using 3 mechanisms: impacting the immune system, hormonal system of the host and absorbing minerals [7]:

\section{IMPACTING THE IMMUNE SYSTEM}

The microflora inhabiting the digestive tract stimulates the immune system through speeding up the production of antibodies. In the last few years studies have shown, that the immune system has a great impact on rebuilding the bone tissue through the impact on the RANKL-RANK-OPG system. Thanks to that, we can safely associate changes in the microflora of the digestive tract with pathological mechanism of the bone tissue using the immune system [7]. Recently conducted studies on mice without the intestinal microflora showed, that the lack of the ecosystem in the light of the intestines has impact on the immune system of the host. In comparison to control group, the animals had lower level of proinflammatory cytokines and less helper T cells, which directly impacted the RANKL-RANK-OPG system, limiting the action of osteoclasts through directly lowering their precursors in the bone marrow $[6,8]$.

\section{IMPACTING THE HORMONAL SYSTEM}

The hormonal system has a great impact on the metabolism of supporting tissues. One of the greatest impacting factors is insulin-like growth factor type I (IGF-1), which synthesis is stimulated by the growth hormone (GH). IGF-1 (insulin-like grow th factor type I) boosts the differentiation and growth of osteoclasts, osteocytes and chondrocytes. It is also responsible for maintaining the correct interaction between bone tissues and cartilage tissues. Homeostasis is also greatly impacted by sex hormones, estrogens and androgens [7].

Research conducted in the last few years consider the digestive tract bacterial flora as a new „hormonal organ”, which impacts the whole organism. Microorganisms inhabiting the light of intestines synthesize hormones or products similar in composition to hormones and impact the synthesis of hosts hormones, impacting the homeostasis of the organism. Among other things, the $y$ impact the synthesis of IGF-1 $[12,13]$. A decrease of IGF- 1 can also be observed in mice without the bacterial microflora with additional loss of bone tissue [8]. Resettlement of the digestive tract with the microflora caused the increase of IGF-1 additionally boosting the bone density and bone growth [13].

The intestinal microbiome also impacts the sex hormones. In mice, who were given antibiotics the level of estrogens was lower. Lower level of sex hormones increases the permeability of the intestinal barrier at the same time contributing to appearance of inflammatory states of the digestive tract, which also negatively impacts the metabolism of bone tissue [13]. Research conducted on mice without the bacterial microflora also showed, that until achieving sexual maturity in both genders the results were similar. Differences can be spotted only in later life [6].

\section{IMPACTING THE ABSORPTION OF MINERALS}

Correct diet plays a vital role in formation and maintaining the correct bone mass, especially the adequate number of minerals. One of the most important minerals in this case is calcium, which makes the majority in building the skeletal system. Another very important mineral is vitamin $\mathrm{D}$, which is responsible for absorption of calcium. Phosphorus is another important element, but more important is maintaining the balance between these minerals. 
Besides the correct minerals, we must focus our attention to absorption, which is controlled by the microorganisms inhabiting the digestive tract. They impact, among other things, the absorption of calcium and vitamin $\mathrm{D}$. The microflora impacts the absorption of calcium through short chain fatty acids which are being made in the process of fermentation, which lower the $\mathrm{pH}$ of the intestines. Low $\mathrm{pH}$ helps the absorption of calcium [14]. The microorganisms inhabiting the light of the intestines impact the metabolism of the bone tissue. The positive impact of the fatty acids is not only connected to lowering the $\mathrm{pH}$ of the intestines, but their impact of boosting the process of rebuilding of intestinal epithelial cells [13].

A special impact of micro-flora in correct absorption of minerals was confirmed by studies involving prebiotics, probiotics and their combination in form of symbiotics. The usage of these substances positively impacted the absorption of calcium. Lactobacillus salivarus in form of probiotics increased the absorption of calcium by enterocytes in cell culture. Studies performed on rats growing and mature, which were given prebiotics proved to have an impact on increasing the absorption of calcium and increased the participation of calcium in skeletons of these animals. Supplementation of prebiotics in young women and teens increased the absorption of calcium $[13,15]$.

\section{RELATIONSHIP OF DISORDERS IN DIGESTIVE TRACT MICROFLORA AND OSTEOPOROSIS}

Osteoporosis is a metabolic sickness of bone tissue, which is responsible for weakening the bones. In result, low energetic fraction may appear. It is a disease which is caused by pathological changes in the process of rebuilding the bone tissue which is connected to a disbalance of osteogenesis and osteolysis processes. Contributing to the appearance of this disease are mostly genetic and environmental factors [16].

One of the factors impacting the metabolism of the bone tissue in the females is the level of estrogens, which lowers in the later ages of life. It is connected to lower secretion of these hormones by gonads [17]. The impact of estrogens on metabolism of bone tissue is proven by studies on animals, which had the female gonads removed or had the sex hormones impact blocked which lead to increased loss of bone mass [12]. Acquired results from woman during menopause, in which physiologically there is a restriction of action of gonads and lowered secretion of estrogens also confirm the impact of those hormones on rebuilding the bone tissue. Loss of bone mass and lowering of the mineral density can be observed, which is the direct cause of osteoporosis [18].

In the last few years studies were performed, linking the digestive tract micro-flora to the appearance of osteoporosis. These studies were performed on animal models, in which in order to bring up osteoporosis ovariectomy is performed or the sex hormones action is inhibited, which causes the resorption of bone to slow down and osteoporosis to appear.
Study performed by Li et al. conducted on 3 groups of mice: control group, which had the bacterial flora, mice without the bacterial flora, and mice without the bacterial flora, which were resettled with the bacterial flora, in order to regulate disturbances which this species had (immunological problems, involving less helper $\mathrm{T}$ cells). In all researched groups in order for the osteoporosis to appear a $\mathrm{GnRH}$ (gonadotropin-releasing hormone) agonist leuprolide was used. Supplementation of this substance which blocks the action of steroid hormones contributed to the increase in resorption of bone tissue in the control group and the resettled group, but not in the group without the bacterial flora [19]. This proves, that the digestive tract micro-flora has an impact on the metabolism on bone tissue.

In order to control if the microorganisms inhabiting the digestive tract have an effect on this disease (osteoporosis) in the experimental group infused with osteoporosis probiotic bacteria were used such as: Lactobacillus reuteri. Acquired results in this study show, that the usage of probiotics in the course of osteoporosis lowers the resorption of bone tissue through lowering the activity of osteoclasts [20].

\section{RELATIONSHIP BETWEEN INFLAMMATORY BOWEL DISEASES AND OSTEOPOROSIS}

Disturbances in the micro-environment can be caused by inflammatory diseases, which can lead to increasing the danger of osteoporosis to appear, which weakens the bone tissue causing the low-energetic fractures to appear [12]. Changes in bones during nonspecific inflammatory bowel diseases is connected to disturbances of absorption of calcium and vitamin $\mathrm{D}$.

The inflammatory bowel diseases involve: ulcerative colitis and Chron's disease. In patients with aforementioned diseases the risk of osteoporosis to appear is, respectfully, $16-77 \%$ and $5-40 \%$. Also the frequency of fractures is increased and is $40-60 \%$. During the diseases the risk of osteoporosis to appear in women and men balances itself [21]. Greater risk of osteoporosis to appear is connected to the decrease of bone mineral density, which causes the osteopenia to appear and osteoporosis to develop [22].

The process of losing bone mass in patients with inflammatory bowel diseases is not fully known. First studies suggested, that the medicine used in the diseases of the digestive tract, such as corticosteroids have an impact on losing the bone mass. The appearance of metabolic diseases of bone tissue in patients with inflammatory bowel diseases may result from disturbances in absorption of dietary nutrients [22]. Studies performed on patients with IBD (inflammatory bowel diseases), who were not given medicine showed, that in these patients the mineral density of bone tissue is decreased. However, in blood plasma of those patients, a higher level of proinflammatory inteleukines (IL) as: IL 1, IL 6, IL 11, IL 15, IL 17, which are recognized as stimulating agents of the osteoclastogenesis process. The mentioned results show, that not only medicine used in treatment of IBD or disturbances in absorption of dietary nutrients cause the decrease of BMD, but the inflammatory 
process itself which stimulates the activity of osteoclasts, which are responsible for the resorption processes in bone tissue [22].

IBD also affect the youth and children. Children suffering from IBD show dwarfing, which can be present in later life. Disturbances in growth and development of such young organism are connected to pathophysiological changes in metabolic changes of bone tissue, so impairment of both processes happening in bone tissue growth (osteolytic process and osteogenesis process). Children, in which IBD was diagnosed also show reduction of bone tissue remodeling process in trabecular bone and lowering the level of bone turnover markers. Because of the treatment, the level of bone turnover markers returns to normal. However, the mineralization of bone tissue still isn't correct [23]. In available literature there is no studies that would show the impact of IBD on the metabolism of bone tissue and about creation of peak bone mass in children and youth with those diseases that are long term. Available information on IBD on skeletal system of children and youth is short term. Acquired results from these types of studies show, that bone mass in children with IBD is lower in comparison to healthy children. Disturbances in growth and development in children and youth because of the diseases may lead to development of incorrect peak bone mass, which in the adult life may lead to the appearance of osteoporosis [23].

As it is shown in mentioned literature, the IBD affect not only adults with fully developed bone mass, but also children and youth during the development, which negatively affects the growth of their skeletons, which may lead to appearance of bone tissue diseases.

\section{DISTURBANCES OF DIGESTIVE TRACT MICROFLORA AND IT IS EFFECT ON DEVELOPMENT OF ARTHROSIS}

Arthrosis is a degenerative disease, which is connected to degeneration of cartilage. This disease contributes to the appearance because of the damage to cartilage. In advanced cases it may lead to full disability. A lot of factors may lead to arthrosis to appear, and can be split into 2 categories: genetic and environmental. It can be safely assumed, that the etiology of this disease has a multifactorial character. Research conducted over the years prove, that for the arthrosis to appear there may be a long term inflammatory state of the entire organism [24]. The intestinal microflora affects not only the physiology of the intestines, but the entire organism of the host. Disturbances of the micro environment of intestines affect the appearance of IBD which are characterized by being long term and maintaining a constant inflammatory state of the organism. Research conducted over the years prove, that the disturbances in the intestinal microflora affect the appearance of autoimmune diseases such as rheumatoid arthritis or celiac disease [22]. In the last years we are trying to tie the disturbances of the intestinal micro-environment with the development of arthrosis, because the changes in the intestinal microflora negatively affect the homeostasis of the entire organism.
Available results of studies conducted on animals, whose microflora contents were disturbed by supplementation of multi targeted antibiotics, or animals without the micro flora. These studies show, that changes in the intestinal micro environment negatively affect the metabolism of the bone tissue $[8,9,11]$.

Basing on the mentioned results it can be assumed, that the disturbances in the microflora negatively affect the metabolism of the cartilage tissue, which in later life may lead to the appearance of arthritis. However in the available literature there is no evidence proving this hypothesis. Because of that it can be assumed, that the impact of disturbances of the intestinal microflora on changes happening in cartilage tissue can be a new field for research.

\section{CONCLUSION}

The impact of changes in digestive tract microflora on metabolism of the bone tissue is a new field for research. In available literature in the last few years the results prove, that the disturbances of the microflora of the digestive tract impact on the metabolism of bone tissue. These studies were conducted on experimental animals. There is however a lack of data about humans. Acquired results can be transcribed to humans only partially. On the other half, disturbances in the microenvironment of the digestive tract lead to the appearance of IBD of different character. In available literature there is a lot of information of the negative impact of the IBD on peak bone mass of the patients and the growth of frequency of osteoporosis, which leads to higher risk of low energy fractures. In the last few years there is also information about how important the usage of probiotics, prebiotics and symbiotics is, which positively impact the microflora of the digestive tract, which indirectly impact the homeostasis of the entire organism, including the skeletal system. The impact of the microbiome on the metabolism of bone tissue is already confirmed, however the mechanism of that is not yet known. The impact of changes of the contents of microorganisms inhabiting the light of the intestines is also not yet explored. The studies involving the changes in the microenvironment of the intestines on the metabolism of the supporting tissues is a new field for research, which gives the field for new studies to be performed in order to better know the interactions between the microbiome of the intestines and the metabolism of those tissues.

\section{REFERENCES}

1. Zhang YJ, Li S, Gan RY et al. Impacts of gut bacteria on human health and diseases. Int J Mol Sci. 2015;16(4):7493-7519. doi: 10.3390/ ijms16047493.

2. Neish A.Microbesingastrointestinal health and disease.Gastroenterology. 2009;136:65-80. doi: 10.1053/j.gastro.2008.10.080.

3. Mroczyńska M, Libudzisz Z, Gałęcka M et al. Mikroorganizmy jelitowe człowieka i ich aktywność metaboliczna. Prz Gastroentero. 2011;6(4):218-224.

4. Dethlefsen L, Eckburg PB, BikEM et al. Assembly of the human intestinal microbiota. Trends Ecol Evol. 2006;21(9):517-523. 
5. Kądzielska J, Obuch-Woszczatyński P, Pituch H et al. Clostridium perfringens jako czynnik etiologiczny biegunki poantybiotykowej. Post Mikrob. 2012;51:17-25.

6. Ibáneza L, Rouleaua M, Wakkacha A et al. Gut microbiome and bone. Joint Bone Spine. 2019;86:43-47. doi: 10.1016/j.jbspin.2018.02.008.

7. Xu X, Jia X, Mo L et al. Intestinal microbiota: a potential target for the treatment of postmenopausal osteoporosis. Bone Rech. 2017;5(17046):1-18. doi: 10.1038/boneres.2017.46.

8. Sjögren K, EngdahlC, Henning P et al. The gut microbiota regulates bone mass in mice. J Bone Miner Res. 2012;27(6):1357-1367. doi: 10.1002/ jbmr.1588.

9. Schwarzer M, Makki K, Storelli G et al. Lactobacillus plantarum strain maintains growth of infant mice during chronic undernutrition. Science. 2016, 351:854-857. doi: 10.1126/science.aad8588.

10. Blanton LV, Charbonneau MR, Salih T et al. Gut bacteria that prevent growth impairments transmitted by microbiota from malnourished children. Science. 2016;351(6275):1-18. doi: 10.1126/science. aad3311.

11. Guss JD, Horsfield MW, Fontenele FF et al. Alterations to the gut gicrobiome impair bone strength and tissue material properties. J Bone Miner Res. 2017;32(6):1343-1353. doi: 10.1002/jbmr.3114.

12. Zhang J, LuY, Wang Y et al. The impact of the intestinal microbiome on bone health. Intractable Rare Dis Res. 2018;7(3):148-155. doi: 10.5582/ irdr.2018.01055.

13. Yan J, Herzog JW, Tsang K et al. Gut microbiota induce IGF-1 and promote bone formation and growth. Proc Natl Acad Sci USA. 2016;113(47):7554-7563.

14. Dolińska B, Mikulska A, Ryszka F. Promotory wchłaniania wapnia. Ann Acad MedSiles. 2009;63(1):76-83.

15. Mojka K. Probiotyki, prebiotyki i synbiotyki - charakterystyka i funkcje. Problemy Higieny i Epidemiologii. 2014, 95(3):541-549.

16. Czerwiński E., Osieleniec J., Badurski J., Marcinowska-Suchowierska E., Czerwińska I.:Współczesna diagnostyka osteoporozy. Family Medicine and Primary Care Review. 2008, 10, 3:821-829.

17. Janiszewska M., KulikT., Dziedzic M., Żołnierczuk-Kieliszek D., Barańska A.: Osteoporoza jako problem społeczny - patogeneza, objawy i czynniki ryzyka osteoporozy pomenopauzalnej. Probl Hig Epide. 2015;96(1):106-114.

18. Tkaczuk-Włach J, Sobstyl M, Jakiel G. Osteoporoza - obraz kliniczny, czynniki ryzyka i diagnostyka. Prz Menopauz. 2010;2:113-117.

19. LiJY, Chassaing B, Tyagi AM et al. Sex steroid deficiency-associated bone loss is microbiota dependent and prevented by probiotics. J Clin Invest. 2016;126(6):2049-63. doi: 10.1172/JCl86062.
20. Ohlsson C, Engdahl C, Fåk F, et al. Probiotics protect mice from ovariectomy-induced cortical bone loss. PLOSONE. 2014;9(3):e92368:18. doi: 10.1371/journal.pone.0092368.

21. MihellerP,GesztesW, LakatosPL. Manipulating bonedisease in inflammatory bowel disease patients. Ann Gastroenterol. 2013;3:148-155.

22. Lima CA, Lyra $A C$, Mendes CMC et al. Bone mineral density and inflammatory bowel disease severity. Braz J Med Biol Res. 2017, 50(12):e6374:1-8. doi: 10.1590/1414-431X20176374.

23. Pappa H, Thayu M, Sylvester F et al. Skeletal health of children and adolescents with inflammatory bowel disease. J Pediatr Gastroenterol Nutr. 2011;53(1):11-25. doi: 10.1097/MPG.0b013e31821988a3.

24. Szychlińska MA, Di Rosa M, Castorina A et al. A correlation between intestinal microbiota dysbiosis and osteoarthritis. Heliyon. 2019;12:5(1) e01134:1-26. doi: 10.1016/j.heliyon.2019.e01134.

\section{ORCID and contributionship:}

Agnieszka Tomczyk-Warunek - 0000-0002-5007-7327 A,B,DF Anna Dubiel - 0000-0003-3594-9382 B,D,E

Ewa Poleszak - 0000-0003-4359-3953 ${ }^{B, D}$

Rudolf Blicharski - 0000-0002-3538-8688 ${ }^{B, D}$

Maciej Dobrzyński - 0000-0003-2368-1534 ${ }^{B, D}$

\section{Conflict of interest}

Authors declare no conflict of interest

\section{CORRESPONDING AUTHOR \\ Agnieszka Tomczyk-Warunek}

Chair and Department of Rehabilitation and Orthopaedics,

Medical University in Lublin, Lublin, Poland

8 (SPSK Nr 4) Jaczewskiego str., 20-090 Lublin, Poland

tel: +48 665828618

e-mail:a.tomczykwarunek@gmail.com

Received: 06.07.2020

Accepted: 07.09 .2020

A - Work concept and design, B - Data collection and analysis, C - Responsibility for statistical analysis, D-Writing the article, $\mathbf{E}$-Critical review, $\mathbf{F}$ - Final approval of the article 